\title{
CERVICAL SPINE INJURIES RESULTING FROM COLLISION SPORTS*
}

\author{
By L. S. Kewalramani, ${ }^{1}$ M.D., M.S.Orth, and Jess F. Krauss, ${ }^{2}$ M.P.H., Ph.D. \\ ${ }^{1}$ Louisiana Rehabilitation Institute, LSU School of Medicine, 1542 Tulane Avenue, \\ New Orleans, Louisiana 70II2. ${ }^{2}$ Professor of Epidemiology, School of Public Health, \\ Room 76-0780, University of California, Los Angeles, California 90024
}

\begin{abstract}
Acute traumatic lesions of spine as a result of 'collision sports' such as football, wrestling, and boxing are of particular significance since these injuries most frequently involve the cervical spine in males, and the resulting neurologic deficit if permanent, is tetraplegia. Forty-six (3.5 per cent) of 1305 patients with spinal cord injury sustained cervical spinal cord trauma during collision sports and 84 per cent of these remained tetraplegic. Their neurological patterns of deficit, radiological abnormalities, mechanism of injury and management are presented in detail. To minimise the severity of neurological deficit some preventive measures are also outlined.
\end{abstract}

Key words: Cervical spine injuries; Paralysis; Collision sports; Football; Wrestling; Boxing.

'Collision sports' such as football, wrestling and boxing, have attracted millions of adolescent and young adult participants in the United States over the past several decades. The energy transmitted on collision during these sports has resulted in a number of severely injured players every year. Frequently, the injury is to the cranio-cervical region and the resulting neurological deficit if permanent, is tetraplegia. In recent years considerable interest has arisen with regard to athletic injuries (Football in particular) and attempts have been made to establish pathomechanics of these injuries and to develop ways of preventing them. At present, no estimate can be made of the magnitude of this problem since the present reporting systems are inadequate. In addition, there is understandable reluctance on the part of coaches and athletic administrators to publicise the problem of such injuries. Often the players themselves do not complain or admit to injury unless it is a serious one.

Several authors have reported on small clinical series of head and neck injuries in football Alley (1964); Chrisman, Snook et al. (1965); Schneider (1973); Dolan et al. (1975); Funk and Wells (1975); Albright, Moses et al. (1976); Brooks and Young (1976); Torg, Moyers and Nichols (1976); Torg, Quedenfeld et al. (1977); Torg, Truex et al. (1979); but there is a paucity of references in the literature about the injuries to spine sustained during wrestling and boxing. The objective of this paper is to report a series of acute traumatic lesions of the cervical spine sustained by athletes involved in collision sports. All patients had injuries solely to the cranio-cervical region, with varying degrees of neurological deficit at the time of admission to the hospital. Clinical features, radiological abnormalities and

* Presented in part at the 39th Annual Assembly of the American Academy of Physical Medicine \& Rehabilitation, 3 November, 1977.

Supported in part by Research and Training Center \#4 (RSA grant I6-P-56813/6-16). 
the mechanism of injury and outcome are described. Possible methods of prevention of such injuries are also discussed.

\section{Materials and Methods}

From January I96I through to December I976, II65 patients with spinal cord injuries have been admitted at the Texas Institute for Rehabilitation and Research, Houston, Texas, and at UCD-Sacramento Medical Center, Sacramento, California, from July I 970 through to June I976, I40 patients with spinal injuries were admitted. There were only 46 patients with acute traumatic lesion of the spine from collision sports. Medical records of these patients were exhaustively

\section{TABLE I}

\begin{tabular}{l} 
Components of ventroflexion injury to the cervical spine \\
\hline Increased interspinous space \\
Increased intervertebral space (posterior) \\
Ventroluxation/dislocation of upper vertebral body \\
Unilateral or bilateral facet locking or facet fracture \\
Avulsion fracture of lower spinous processes \\
Fracture of vertebral body \\
- wedge \\
- tear drop \\
- burst \\
Anterior atlantoaxial subluxation with/without fracture of odontoid process. \\
(three or more criteria needed)
\end{tabular}

TABLE II

Components of retroflexion injury to the cervical spine

Crowding of spinous processes/neural arches

Intervertebral space (anterior) increased

Retroluxation/dislocation of vertebral body

Fracture of spinous process/neural arches

Chip fracture at anterior superior/inferior angle of vertebral body

Posterior atlanto axial subluxation with/without fracture of odontoid process.

(Two or more components necessary) or

Absence of any radiographic abnormality.

\section{TABLE III}

Components of vertical loading injury to the cervical spine

Burst fracture of vertebral body

Narrow intervertebral space

Interspinous space unchanged/decreased

Fracture of neural arch of atlas with dispersion of condyles

Fracture of pedicle of $\mathrm{C}_{2}$ with ventroluxation of $\mathrm{C}_{2}$ or $\mathrm{C}_{3}$ 
reviewed and all available radiographs were carefully examined for analysis of the mechanism of injury. Radiologic criteria for classification of the mechanism of osteoarticular injury were established in the beginning of this study (Tables I-III). History, clinical findings and radiological abnormalities were considered in combination to establish the mechanism of injury.

\section{Results}

Forty patients sustained injury in football games or practice, five were injured in wrestling and one during a boxing match. Twenty-four football injuries occurred in school or college sports and eight during sandlot football. Three of the five wrestling injuries also occurred in school or college. Ten patients were injured during 'spearing or stick blocking', six from 'head butting', three 'head-on tackles' and two were 'knee to head' injuries. Five other patients admitted having practised spearing before, but this was not the immediate cause of injury in those patients.

All 46 patients were males, youngest patient was I 4 years old and 65 per cent were I6-20 years old. Thirty-nine of 40 patients injured in football were 20 years or less, in age. There were 36 whites, eight blacks, one Mexican and one LatinAmerican. All injuries involved the cervical region only. There were no thoracic or lumbar injuries.

\section{Neurological features}

Since neurological injuries are determined during the initial clinical examination and, in fact, provide basis for determining what X-rays need to be obtainedthey will be discussed before the radiological findings. At the time of admission to the hospital every patient had varying degrees of neurological deficit.

Two patients (4 per cent) complained of paraesthesiae in upper limbs but had no other objective neurological finding.

Thirty-six patients (75 per cent) had a neurological picture of complete traumatic transverse myelitis below the level of lesion. One of them had motor $\mathrm{C}_{7}$ tetraplegia with some sensory preservation to $\mathrm{T}_{2}$ and complete loss below. Nine were tetraplegics below $\mathrm{C}_{4}$, I 4 below $\mathrm{C}_{5}$, six below $\mathrm{C} 6$, and two each below $\mathrm{C}_{7}, \mathrm{C}_{2}$ and $\mathrm{C}_{3}$. Only one patient was classified as tetraplegic below $\mathrm{C} 8$.

Four patients ( 8 per cent) had neurological features of acute anterior cervical cord syndrome with preservation of position and vibratory sensation below the level of the lesion. One each, below $\mathrm{C}_{2}, \mathrm{C}_{4}, \mathrm{C}_{5}$ and $\mathrm{C} 6$.

Neurological features consistent with acute central cervical cord syndrome were found in only four patients (8 per cent), one each below $\mathrm{C}_{3}, \mathrm{C}_{4}, \mathrm{C}_{5}$ and $\mathrm{C} 6$.

One patient experienced brief unconsciousness following his injury and another patient gave history of ankylosing spondylitis of about 20 years duration.

\section{Osteoarticular injuries}

Roentgenologic evidence of osteoarticular injury was present in 42 (9I per cent) of the 46 patients (Table IV).

There were $4 \mathrm{I}$ subluxations in 38 patients, $2 \mathrm{I}$ subluxations at $\mathrm{C}_{4} / 5$, I I at $\mathrm{C}_{5} / 6$, five at $\mathrm{C}_{6} / 7$, three at $\mathrm{C}_{3} / 4$, and one at $\mathrm{C}_{2} / 3$. Three patients had subluxations at two levels, all at $\mathrm{C}_{4} / 5$ and $\mathrm{C}_{5} / 6$ levels. In 32 of the 38 patients, subluxations/ dislocations were associated with fractures of vertebral bodies and/or neural arch. 


\section{TABLE IV}

Osteoarticular injuries

(Collision sports)

\begin{tabular}{|c|c|c|}
\hline $\begin{array}{c}\text { Fractures } \\
\text { Vertebral body }\end{array}$ & Neural arch & Luxations \\
\hline $\begin{array}{lr}\mathrm{CI}_{1} & \\
\mathrm{C}_{2} & \mathrm{I} \\
\mathrm{C}_{3} & 2 \\
\mathrm{C}_{4} & 4 \\
\mathrm{C} 5 & 25 \\
\mathrm{C} 6 & \mathrm{II} \\
\mathrm{C} 7 & 2\end{array}$ & $\begin{array}{l}3 \\
2 \\
3 \\
4 \\
2\end{array}$ & $\begin{array}{ll}\mathrm{CI} / 2 & \\
\mathrm{C} 2 / 3 & \mathrm{I} \\
\mathrm{C} 3 / 4 & 3 \\
\mathrm{C} 4 / 5 & 2 \mathrm{I} \\
\mathrm{C} 5 / 6 & \mathrm{II} \\
\mathrm{C} 6 / 7 & 5\end{array}$ \\
\hline $\begin{array}{l}\text { Total } 45(35) \\
(\text { ) number of } \\
39 \mathrm{~W} 3 \mathrm{~B} 2 \mathrm{~T}\end{array}$ & $\begin{array}{l}\text { I4 (I2) } \\
\text { ents } \\
\text { chip }\end{array}$ & 4I (38) \\
\hline
\end{tabular}

Of the six patients with only subluxations and no fractures of vertebrae, four were at $\mathrm{C}_{4} / 5$ and one each at $\mathrm{C}_{3} / 4$ and $\mathrm{C}_{6} / 7$.

Thirty-five patients sustained 45 vertebral body fractures; 25 fractures of $\mathrm{C}_{5}$ vertebral body, I I of $\mathrm{C}_{6}$, four of $\mathrm{C}_{4}$, two of $\mathrm{C}_{3}$, two of $\mathrm{C}_{7}$, and one of $\mathrm{C}_{2}$. Ten patients had fractures of two vertebral bodies-eight of $\mathrm{C}_{5}$ and $\mathrm{C} 6$, one of $\mathrm{C}_{4}$ and $\mathrm{C}_{5}$, and one of $\mathrm{C}_{2}$ and $\mathrm{C}_{3}$. Categories of fractures included two 'tear drop', three 'burst' and 39 'wedge'. One fracture was an avulsion (chip) fracture of anterior inferior angle of $\mathrm{C}_{2}$ vetrebra. Fractures of vertebral body were associated with subluxation/dislocation in 3I patients. Twelve patients incurred $\mathrm{I} 4$ fractures of the neural arch-three at $\mathrm{C}_{1}$, two at $\mathrm{C}_{3}$, three at $\mathrm{C}_{4}$, four at $\mathrm{C}_{5}$, and two at $\mathrm{C}_{6}$. All fractures of the neural arch were associated with both fracture of the vertebral body and subluxation except for one patient in which fracture of the spinous process was associated with subluxation only.

Myelography was performed in four patients, three of whom had additional radiological evidence of osteoarticular injury on plain X-rays. Extradural defect and partial block were found in only one patient; the myelogram was reported normal in three patients.

Based on the present radiological criteria for classification of osteoarticular injuries, 25 patients were classified as ventroflexion/rotation injuries, and ten as retroflexion rotation injuries. In I I patients it was not possible to classify the mechanism of injury with certainty.

\section{Management}

All patients immediately following admission to the hospital, were immobilised by skull traction tongs: Vinke, Gardner-Wells, Crutchfield or Cone Barton tongs. Twenty-seven of the 46 patients underwent some operative procedure on the cervical region. Posterior fusion and wiring was performed on three patients, laminectomy on four patients, and laminectomy with posterior fusion on seven patients, and anterior spondylodesis on ten patients. Three patients underwent laminectomy immediately following the injury and later needed anterior cervical 
fusion for stabilisation of the cervical spine. Twenty-four of the 27 patients who underwent operative procedures remained tetraplegic. The three patients with post operative neurological improvement were incomplete lesions at the time of admission (acute central cervical cord syndrome).

Of the remaining I9 patients who were not operated on, two had paraesthesiae and two were incomplete lesions (one central cervical cord syndrome, one $\mathrm{C}_{7}$ motor and $\mathrm{T} 2$ sensory myelitis). These four patients improved considerably and were independent in all activities of daily living not requiring any assistive devices. The other I5 patients remained tetraplegic.

Nine patients developed complications. Four patients experienced respiratory problems at the time of admission and required tracheostomy within 24 hours. Each patient had a lesion of the spinal cord at or above $\mathrm{C}_{4}$. Two other patients required tracheostomy 6-8 hours following surgery (laminectomy in one and posterior fusion and wiring in the other) because of breathing problems. Three patients developed neurogenic gastroduodenal ulceration and bleeding.

\section{Neurological Outcome}

The two patients who had complaints of paraesthesiae on admission improved and by the time of discharge had no complaints and no neurological deficit. The four patients with acute central cervical cord syndrome made good recovery and were ambulatory as well as independent in all activities of daily living at follow-up. The $\mathrm{C}_{7}$ tetraplegic patient with some sensory preservation to $\mathrm{T}_{2}$ showed good functional recovery and was ambulatory.

Of 35 patients with clinical picture of complete transverse myelitis, none showed any neurological improvement. None of the four patients with anterior cervical cord syndrome showed any functional motor or sensory return. Thus, 39 patients were tetraplegic at discharge.

\section{Correlation of Radiological findings with neurological outcome}

Radiological abnormalities of the cervical spine alone are of little importance without consideration of neural structures. It is the relationship of osteoarticular integrity to the neurological deficit that must be analysed.

Thirty-one patients sustained 39 wedge fractures-ten had fractures of two vertebral bodies (nine with two wedge fractures, one with a wedge and a burst fracture). Nine of the ten patients with two vertebral factures were tetraplegic on admission and remained tetraplegic on follow-up. One patient with two wedge fractures had a central cervical cord syndrome and made good recovery.

Three patients had 'burst' fractures. One of these had a 'wedge' fracture in addition to a 'burst' fracture. All three patients remained tetraplegic. Two patients had 'teardrop' fractures. They were tetraplegic following their injury and did not change neurologically.

All I4 patients with second degree subluxation were tetraplegic on admission and remained tetraplegic.

With regard to specific mechanism of injury, 25 patients were classified as ventroflexion injury. Twenty-one of these had a clinical picture of traumatic transverse myelitis, three had anterior cervical cord syndrome and one had central cervical cord syndrome. Retroflexion injury was identified in ten patients, six of which had incomplete lesion (two with central cervical cord syndrome, two with anterior cervical cord syndrome and two with paraesthesiae). Eleven patients could 
not be satisfactorily classified as either ventroflexion or retroflexion rotation injuries. Of these, ten had neurological features of transverse myelitis and one had acute central cervical cord syndrome. Of the four patients with absence of any radiological abnormalities and classified as retroflexion injuries, three remained tetraplegic since they were clinically complete physiologic transection of the cervical spinal cord.

The three patients with normal myelograms on admission remained tetraplegic on follow-up. They were clinically complete lesions.

\section{Discussion}

The National Institutes of Health have estimated that the cost to society of spinal cord injury is second to that of mental retardation among the neurologic and sensory disorders. Of particular significance in this respect are acute traumatic lesions of the spinal cord as a result of 'collision sports', since these injuries always involve the cervical spine and the resulting neurological deficit if permanent is tetraplegia. The term 'contact sports' for football, wrestling and boxing appears to be a misnomer, since magnitude of forces and energy transmitted during these sports are tremendous, amounting to collision. More appropriate is the term 'collision sports'. To date, no data exists which indicates the true incidence of injuries because the few available reporting systems which are operating are incomplete and inadequate. The NCAA (National Collegiate Athletic Association) has a reporting system, but it focuses solely on collegiate football injuries (excluding football injuries at high school and pre-high school levels and sandlot football). Recently (1975), the National Athletic Trainers' Association and Temple University Center for Sports Medicine and Science combined their resources in order to establish a National Football Head and Neck Registry which, hopefully, will provide data on injuries at the pre-high school and high school levels. For injuries which occur outside the school setting, there is no reporting system at present.

Schneider (1972) documented 78 cervical spine injuries due to football accidents over a period of 5 years (I959-1964) with 56 cervical fracture dislocations, of which 30 resulted in complete permanent tetraplegia and 16 deaths. This gives an annual incidence of $15.6 /$ year in 50 states. On the other hand, Torg, Quedenfeld, et al. (1977) reported 12 cases of severe and catastrophic neck injuries from football which occurred during 1975 in two states only (Pennsylvania and New Jersey). From these data it is very difficult to say what percentage of injuries occurred from football nationally.

We conducted an epidemiologic study of the acute traumatic lesions of the spinal cord in the 18 counties of Northern California with a total population of 5.8 million for years 1970 and I97I (Kraus, I975). Of the 6I9 persons identified with spinal cord injury 320 survived and seven of these injuries were due to collision sports (six football and one wrestling), approximately $I \cdot I$ per cent of the total and 2.4 per cent of the surviving group of patients with spinal cord injury. This gives an annual incidence rate of $0.6 /$ million population. Projected nationally, this rate indicates an annual total of IOO-I IO new spinal cord injuries due to collision sports. In the present series of 1305 patients 46 were injuries to spinal cord from collision sports, i.e., 3.5 per cent of all spinal cord injuries admitted at the two institutions.

Although several reports have been published in recent years on head and neck injuries in football, there is paucity of literature regarding injuries sustained during wrestling and boxing.

Researchers generally agree that ventroflexion (hyperflexion) injuries are the 
most severe and dangerous injuries in football and the most commonly involved regions are $\mathrm{C}_{4} / 5$ and $\mathrm{C}_{5} / 6$. In the present series 23 of 40 (57 per cent) patients injured in football sustained ventroflexion injuries, and 70 per cent of these were at $\mathrm{C}_{4} / 5$ and $\mathrm{C}_{5} / 6$ levels. 'Knee to head' injury, 'head butting' and falls while executing tackles have been known to cause ventroflexion injuries. With this mechanism of injury, fracture and/or subluxation of the vertebral body is often associated with contusion of the spinal cord. In this series 20 of the 23 patients with this mechanism of injury had clinical picture of transverse myelitis while three had anterior cervical cord syndrome. We agree with Funk and Wells (1975) that flexion dislocation at $\mathrm{C}_{4} / 5$ and $\mathrm{C}_{5} / 6$ levels resulting in tetraplegia is the most serious mechanism of injury in the young football athlete. Although Melvin, Dunlop, et al. (1965) pointed out that during falls the bar of the helmet might get caught in muddy ground and cause forced flexion with fracture dislocation of the cervical spine; it is difficult to say from the information available in the present series, however, if this were an aetiologic factor.

Schneider (1973) reported that serious neurologic damage could result from retroflexion (hyperextension) of the cervical spine while tackling or falling down during 'knee-to-faceguard' injury, 'faceguard' tackle or 'stick blocking'. The neurological deficit in those patients may be either due to vascular insufficiency to the cervicomedullary region or due to direct trauma to the spinal cord with or without evident osteoarticular injury. In the present series, seven patients received retroflexion injury from football, only four of which had radiological evidence of osteoarticular injury. Five of the seven patients had incomplete lesions of the cervical spinal cord. Schneider (1973) identified several instances in which the upper cervical spinal cord was severely damaged without there being any evidence of osteoarticular injury, but in the present series, the three patients with normal radiographs had incomplete lesions of the cervical spinal cord and two of these were ambulatory with minimal or no neurological deficit. Funk and Wells (1975) reported that they have encountered hyperextension injury less frequently and they have never seen either death, serious spinal cord damage, fracture, or dislocation directly attributable to hyperextension. We agree that retroflexion injuries occur less frequently, but in our experience they have often been associated with moderately severe neurological deficit and osteoarticular injuries. The protective helmet itself could also prove hazardous during the 'faceguard tackle' or 'knee-to-faceguard' injury, when the lever of the faceguard with the CI vertebra as fulcrum drives the posterior margin of the helmet downward and forward into the cervical spinal cord, causing a retroflexion injury.

Another type of injury which may be sustained in football is vertical stress or impaction injury at the atlanto-occipital and atlantoaxial levels with or without neurological deficit. This may occur when a player makes a 'head on' tackle or 'head butting'. 'Lateral stretch' or traction injuries have been caused by a variety of mechanisms-'head butting', 'stick blocking', 'clothes lining'. Often what occurs is a forceful lateral flexion of the cervical spine in the opposite direction of the impact while the shoulder is depressed downwards, causing traction injury to the brachial plexus. Although this is considered to be the most common injury in college and professional football, in the present series there were no cases which could be classified as vertical stress or lateral traction injuries.

It appears that the patients with more severe, i.e., with irreversible neurological deficit and radiological abnormalities at $\mathrm{C}_{4} / 5$ and $\mathrm{C}_{5} / 6$ levels, had suffered ventroflexion injuries while the patients with less severe neurological deficit were retroflexion injuries. Only eight patients of 40 (20 per cent) with football injuries were 
playing without any protective equipment, and 24 patients had a complete set of protective gear. We agree with Schneider (1973), Torg, Moyers et al. (1976) and Albright, Moses et al. (1976) that the athletes playing with protective equipment might be striking harder than the sandlot group, with a false sense of security and some might have been using the helmet as the primary assault weapon.

Wrestling and boxing: The present series includes five male patients injured while wrestling. Mechanism of injury includes two with retroflexion and two with ventroflexion. The remaining patient's mechanism of injury could not be satisfactorily classified. Three patients had complete sensory and motor loss below the level of lesion. One patient complained of paraesthesiae in upper and lower limbs; while another patient had the neurological features of an acute central cervical cord syndrome. All patients showed radiographical evidence of osteoarticular injury. It is interesting to note that the patient with paraesthesiae was suffering from ankylosing spondylitis and sustained a fracture with minor trauma through the C6-7 intervertebral space, fracturing the ossified anterior longitudinal ligament.

The patient who received injury to his cervical spine during a boxing match sustained a retroflexion injury with fracture of $\mathrm{C} 6$ vertebral body and was tetraplegic below $\mathrm{C}_{7}$. In addition, he had a fracture of the neck of the fifth metacarpal on the right side.

\section{Preventive measures}

Although a certain number of serious injuries cannot be avoided in collision sports, we do not believe that the individual (player) or society has to pay such a high price as death or permanent severe handicap due to neurological lesion. It should be the goal of every player, coach and equipment manufacturer to do everything possible to make these sports safe and to avoid catastrophes. In an attempt to reduce the severity of injury, it is essential to take several protective measures which should include:

I. Require a preliminary physical examination of athletes-the individual with complaints of tingling, numbness or local muscle atrophy or seizures must be thoroughly investigated. Also, obtain prior to participation AP and lateral views of the cervical spine for comparison following any trauma and finally identify individuals with evidence of previous osteoarticular injury. The individuals with long neck, poor neck musculature, or those with congenital abnormalities of cervical spine should be watched carefully.

2. Outlaw hazardous tackles such as spearing, stick blocking, karate blow, faceguard tackle, butt tackling, clothes-lining.

3. Incorporate into practice conditioning exercises for neck musculature as well as cardiac functioning.

4. Guard against the misuse of protective equipment-helmet, cervical collar, boxing gloves for offensive purposes.

5. Establish teaching sessions for players, coaches and other officials in order to make them aware of the possibility of fatal injuries. Also inform the public that the possibility of fatal injuries does exist during participation in these sports.

6. Insist on thorough evaluation of all minor or major injuries. The individuals with repeated episodes of trauma must be evaluated carefully. 


\section{SUMMARY}

Of the I305 patients admitted at the Texas Institute for Rehabilitation and Research, Houston, Texas and UCD-Sacramento Medical Center, Sacramento, California, 46 patients ( 3.5 per cent) sustained cervical spinal cord injury during collision sports. Forty patients were injured during football, five during wrestling and one during boxing match. All patients were males-and 65 per cent of these were I6-20 years old. Fifty-eight per cent injuries occurred during school or college sports events. Eighty-seven per cent patients were tetraplegic on admission to the hospital. Radiological evidence of osteoarticular injury was present in 9I per cent patients. Wedge fractures of $\mathrm{C}_{5}$ vertebral body and subluxation or dislocation of $\mathrm{C}_{4} / 5$ were commonest radiologic abnormalities. Fifty-four per cent injuries were ventroflexion rotation injuries. None of the 35 patients with complete traumatic transverse myelitis, and none of the four patients with anterior cervical cord syndrome, showed any functional sensory or motor improvement. Physicians and others should be aware of strategy options for preventing or reducing such injuries.

\section{RÉSUMÉ}

Parmi les 1305 malades ayant été admis à l'Institut du Texas pour la Réhabilitation et la Recherche, Houston, Texas, et au Centre Médical UCD-Sacramento, Sacramento, Californie, 46 malades $(3,5 \%)$ souffraient d'une lésion de la moëlle épinière cervicale, lésion due à un choc reçu en pratiquant un sport. Quarante malades avaient été blessés pendant un match de football, cinq au cours d'un combat de lutte et un au cours d'un combat de boxe. Tous les malades étaient de sexe masculin-et $65 \%$ d'entre eux étaient âgés de $\mathrm{I} 6$ à 20 ans. Cinquante huit pour cent des blessures étaient survenues au collège ou à l'école au cours de manifestations sportives. Quatre vingt sept pour cent des blessés présentaient une tétraplégie lors de leur admission à l'hôpital. Dans $91 \%$ des cas, la radiologie a mis en évidence une lésion ostéo-articulaire. Les anomalies radiologiques les plus courantes étaient des fractures en coin du corps vertébral $\mathrm{C}_{5}$ et une subluxation ou une luxation de $\mathrm{C}_{4} / 5$. Cinquante quatre pour cent des lésions étaient de type rotation ventroflexion. Aucun des 35 malades présentant une myélite transverse traumatique complète et aucun des 4 malades présentant un syndrome de la moëlle cervicale antérieure, n'a subi d'amélioration fonctionnelle sensorielle ou motrice. Les médicins et les autres devraient être conscient des choix de stratégie pour la prévention et la réduction de telles lésions.

\section{ZUSAMMENFASSUNG}

Von den 1305 Patienten, die in dem Texas Institut für Wiedereingliederung und Forschung, in Houston, Texas und dem UCD Sacramento Medical Center, Sacramento, Californien, eingeliefert wurden, hatten 46 Patienten (3.5\%) Nackenrückenmark Verlet-zungen durch Sportarten, in denen Zusammenstösse haufig sind. 40 Patienten frugen bei amerikanischem Fussball, 5 beim Ringen und einer während eines Boxkampfes Verletzungen davon. Alle Patienteen waren männlich-und $65 \%$ davon waren zwischen I6-20 Jahre alt. $58 \%$ der Verletzungen wurden sich während Schul-und Universitätssportfesten zugezogen. $87 \%$ der Patienten waren bei der Einlieferung ins Krankenhaus tetreplegisch. Röntgologischer Beweis liess bei $91 \%$ aller Patienten auf osteoartikulare Verletzungen schliessen. Keilbrüche des $\mathrm{C}_{5}$ Wirbelknochen Körpers und Subluxation sowie Verschiebung von $\mathrm{C}_{4} / 5$ waren die häufigsten röntgologischen Abweichungen. $54 \%$ der Verletzungen waren Ventroflexion Umdrehungsverletzungen. Weder einer der 35 Patienten mit völliger traumatischer umgekehrter Myelitis, noch einer der Patienten mit vorderem Rückenmark Syndrom, zeigte irgendwelche funktionelle Empfinden- oder motorische Verbesserung. Ärzte und andere sollten sich über strategische Moglichkeiten klar werden, um solche Verletzungen entweder ganz $\mathrm{zu}$ verhindern oder sie wenigstens einzudämmen. 


\section{REFERENCES}

Albright, J. P., Moses, J. M. \& Feldick, H. G. et al., (I976). Non-fatal cervical spine injuries in interscholastic football. $\mathcal{F} A M A, \mathbf{2 3 6}, \mathrm{I} 243-\mathrm{I} 245$.

Alley, R. H. (1964). Head \& neck injuries in High School football. $\mathcal{F} A M A, \mathbf{1 8 8}, 4$ I 8-422.

BRooks, W. H. \& Young, A. B. (1976). High School football injuries: Prevention of injury to the central nervous system. Southern Med.F., 69, I258-1260.

Chrisman, O. I., SNOoK, G. A., Stenitis, J. M. \& KeEDy, V. A. (1965). Lateral flexion neck injuries in athletic competition. $\mathcal{F} A M A, \mathbf{1 9 2}, 613-615$.

Dolan, K. D., et al., (1975). Neck injuries in football players. Am. Family Physician, I2, 86-89.

Funk, F. J. \& Wells, R. E. (I975). Injuries of the cervical spine in football. Clin. Orthop. Related Research., 109, 50-58.

Kraus, J. F., Franti, C. F., RigGins \& R. S. et al. (I975). Incidence of traumatic spinal cord lesions. F. Chron. Dis., 28, $47 \mathrm{I}-494$.

Melvin, W. J. S., Dunlop, H. W., Heterington, R. F. \& KerR, J. W. (I965). The role of face guard in the production of flexion injuries to the cervical spine in football. Can. Med. Assoc. F., 93, i I Io.

SCHNEIDER, R. C. (I973). Head and neck injuries in football: Mechanisms, treatment and prevention. Baltimore, Williams \& Wilkins Co.

Torg, J. S., Moyers, R. A. \& Nichols, III, C. E. (1976). Unusual fractures caused by football helmet impact. The Physician \& Sports Medicine. 73-75.

Torg, J. S., Quedenfeld, T. C., Moyers, R. A., Truex Jr., R. A., Spealman, A. D. \& Nichols, III, C. E. (I977). Severe and catastrophic neck injuries resulting from tackle football. F. American College Health Assoc., 25, 224-226.

Torg, J. S., Truex, Jr., R. \& Quedenfeld, T. C., et al. (1979). The National Football Head \& Neck Registry: Report and Conclusions I978. F $A M A$, 24I, I477-I 480. 